\title{
ESTUDO DE VIABILIDADE DA CARONA COMO UM MODAL DE TRANSPORTE ATRATIVO PARA ESTUDANTES DO CAMPUS CURITIBA DA PUCPR
}

\author{
R. L. Witiuk ${ }^{1}$; F. B. von der Osten ${ }^{2}$ \\ ${ }^{1}$ Graduando do curso de Engenharia Civil da Pontifícia Universidade Católica do Paraná \\ ${ }^{2}$ Professora do curso de Engenharia Civil da Pontifícia Universidade Católica do Paraná \\ rafael.witiuk@pucpr.br', fabiana.osten@pucpr.br ${ }^{2}$
}

\begin{abstract}
Resumo: A carona solidária é apontada por muitos como uma alternativa eficiente para a redução do número de automóveis nas vias. Sendo a PUCPR um polo gerador de viagens, durante alguns períodos do dia sobrecarrega o trânsito em seu entorno e apresenta insuficiência de vagas de estacionamento devido à quantidade de estudantes que optam pelo transporte individual. Visando minimizar esta situação e otimizar o espaço físico da universidade, analisa-se a viabilidade da implantação e operação sustentável da carona. Foi utilizada pesquisa realizada pela WRI, que apresenta um diagnóstico da universidade como um todo, em que são estruturados os dados obtidos em três eixos principais: econômico, pessoalidade e acessibilidade, e foi realizada pesquisa com os estudantes do curso de Engenharia Civil onde se busca identificar a origem e destino dos deslocamentos a partir do campus Curitiba, horários usuais de chegada e partida e interesse em oferecer carona. Os resultados mostram que o incentivo econômico é o principal estímulo para adoçáo do sistema. Além disso, houve o interesse manifestado pelos condutores de desviar $1,5 \mathrm{~km}$ e em esperar até 15 minutos. Conclui-se que, demonstrado interesse da comunidade acadêmica, a universidade deve buscar estratégias que permitam a utilização da carona como um sistema perene.
\end{abstract}

\section{Palavras-chave: Carona.}

Abstract: The carpooling is pointed out as an efficient alternative for the reduction of the number of vehicles on the streets. Since PUCPR is a travel generator, which overload traffic in its surrounding during some periods of the day and shows lack of parking spots due to the amount of students who opt for individual transportation. Aiming to minimize this situation and optimize the physical space of the university, this paper analyzes the viability of the implantation and sustainable operation of a carpooling system. A research made by WRI was used, the one which presents a diagnosis of the university as a whole. The following paper structures the obtained data into three main axes: economic, when it comes to in terms of personal preference and accessibility; a survey with Civil Engineering students was made in order to identify the origin-destination of the routes starting at the campus Curitiba, the usual arrival and departure time schedules and the interest to offer rides. The results showed that the economic incentive is the main stimulus for the adoption of the system. In addition, there was an interest expressed by the drivers to deviate $1.5 \mathrm{~km}$ and in waiting up until 15 minutes. With these, it is concluded that having demonstrated the interest of the academic community, the university should seek strategies that allow the use of the ride as a perennial system.

Keywords: Carpooling. 


\section{Introduçáo}

A partir da década de 1930, políticas públicas voltadas para o desenvolvimento do transporte rodoviário e o abandono dos bondes e das ferrovias transformaram profundamente o modo de vida nas cidades assim como a morfologia dos centros urbanos [1]. Tal processo histórico, que se intensificou na década de 1950 a 1970, culminou na situação atual das grandes cidades brasileiras que enfrentam grandes congestionamentos diários, alto custo dos deslocamentos e níveis de poluição cada vez mais elevados.

É importante perceber que a adoção do modelo rodoviário, baseado no automóvel particular, impactou mais do que apenas a questão do transporte. Transformou também o formato das cidades, o modo de vida das pessoas e criou uma cultura centrada no veículo automotor como sinônimo de liberdade e status [2]. Sendo assim, a utilização do carro como modo de deslocamento vai além de questôes econômicas e práticas, dialogando com aspectos culturais e sociais, tornando as mudanças de hábitos de transporte, para modais de transporte ativo ou de massa, ainda mais difíceis.

Dado este cenário, a busca de uma divisão modal com maior participação de modais ativos (pedestre e ciclistas) e de massa (ônibus) depende de grandes esforços do poder público em termos de investimento em infraestrutura e comunicação [1]. Segundo [3] a tradicional morosidade na implementação de políticas públicas voltadas para a criação e adoção de tais medidas, caracteriza-se como um empecilho para a execução de projetos governamentais nesse sentido.

Iniciativas provenientes do setor privado (segundo e terceiro setores) costumam ser vistas como mais ágeis e eficientes. As iniciativas da sociedade civil organizada (terceiro setor), que buscam mitigar o problema, geralmente são propostas sem fins lucrativos, percebidas num primeiro momento como as mais benéficas, mas que trazem como consequência a isenção do Estado em assumir o seu papel de gestor da política de transporte [4]. É consenso entre os estudiosos no assunto que comunidades, ONG’s e organizaçóes estudantis que propóem projetos voltados à carona têm colaborado para trazer soluçôes provisórias eficientes aos problemas de mobilidade urbana e de excesso de veículos.

A prática da carona envolvendo veículos automotores existe desde a metade do século XX através de associaçóes e grupos de trabalhadores de uma mesma empresa e passou a ser incentivada pelo Estado e por grandes corporaçóes a partir dos anos 2000 em decorrência da falta de vagas, custo dos estacionamentos e pela viabilidade de instauração de grupos de carona [5]. Nesse sentido, grandes empresas, autarquias e outros polos geradores de tráfego passaram a incentivar e criar sistemas que viabilizem esse tipo de associação de carona $[6,7]$.

Os sistemas de carona podem ser distinguidos quanto à natureza de viagens e integração dos destinos, podendo ser centralizado, policêntrico ou rede distribuída, e quanto ao tipo de sistemas a interface que utiliza são os aplicativos, sites e grupos em redes sociais $[8,1]$. 
Organizaçóes como universidades, tendo em vista seu papel de vanguarda e inovação, têm potencial para o desenvolvimento desse tipo de sistema de carona. Portanto, justifica-se o desenvolvimento do presente estudo para avaliar a viabilidade de implementação de carona no campus Curitiba da PUCPR. O campus Curitiba da Pontifícia Universidade Católica do Paraná possui uma população de 29.884 usuários diários, é responsável pela geração de aproximadamente 60.000 viagens por dia e detém aproximadamente 4.169 vagas de estacionamento, sendo $76.397 \mathrm{~m} 2$ do seu espaço físico destinado a esse fim [9] aproximadamente $34 \%$ da área da universidade.

Entendendo que a carona poderia contribuir para diminuir a área de estacionamento e tendo conhecimento da pesquisa desenvolvida pela WRI Brasil Cidades Sustentáveis contratada pela PU$\mathrm{CPR}$, cujos resultado estão divididos por escola e não abrange as especificidades dos cursos e aqui mais especificamente o de engenharia civil, foi feita uma pesquisa junto ao curso propondo alternativas a essa realidade. Assim, o objetivo último deste trabalho é analisar a viabilidade de implantação e operação sustentável da carona como medida que vai ao encontro da atual valorização do veículo automotor, ao mesmo tempo em que propicia o aumento da sua taxa de ocupação, contribuindo dessa forma para a diminuição do número de veículos nas ruas e possível otimização do espaço físico da PUCPR.

Ademais, o estudo em pauta apresenta possibilidades de políticas institucionais para incentivar o aumento do número de usuários ofertando e utilizando carona tendo como origem ou destino a universidade.

\section{Metodologia}

No intuito de conhecer os sistemas de carona e os incentivos que podem ser adotados para o uso sustentável desse modal, realizou-se inicialmente o levantamento bibliográfico existente sobre essa temática. Este estudo identificou na literatura os sistemas de carona existentes, [3, 5, 6, 8, 10, 11$]$ bem como os tipos de interfaces utilizadas, sendo elas classificadas em: aplicativos de carona; grupos de carona em redes sociais; e sites de carona.

Num segundo momento, foram analisados os resultados da pesquisa realizada pela WRI Brasil Cidades Sustentáveis em setembro de 2016, solicitada pela PUCPR. Esta pesquisa de origem e destino tinha por fim último subsidiar a elaboração do Plano de Mobilidade da PUCPR. O resultado da pesquisa realizada pela WRI Brasil Cidades Sustentáveis apresentou um diagnóstico da universidade como um todo. Os dados obtidos foram organizados em 3 principais eixos: Econômico; quanto à pessoalidade; e quanto à acessibilidade.

No que diz respeito à pessoalidade, foram elencadas as 4 possibilidades a seguir: Carona entre amigos; colegas de curso; membros da mesma escola; e estudantes da mesma universidade. Quanto aos incentivos de natureza econômica, foram elencadas contrapartidas financeiras em três níveis: Ne- 
nhuma contribuição; contribuição no combustível; contribuição no combustível e estacionamento; e carona em uma outra oportunidade.

Por último, em relação à acessibilidade e praticidade, foram citadas medidas como vagas preferenciais, tempo de espera e desvios de rota. Em relação ao tempo de espera, foram elencadas 4 subcategorias: Sem espera; até 5 minutos; entre 5 e 15 minutos; mais de 15 minutos. No que se refere à desvios de rota foram determinadas 5 subcategorias: Nenhum desvio, até 500 metros, de 500 metros a 1 quilômetro, de 1 quilômetro a 1,5 quilômetros; e mais de 1,5 quilômetros.

Tendo presente os resultados apresentados pela pesquisa da WRI, que sistematizou os dados por escola sem identificar os cursos, definiu-se por aprofundar a pesquisa junto ao curso de engenharia civil da escola politécnica. A pesquisa de origem e destino realizada com os estudantes do curso de engenharia civil buscou identificar aspectos específicos dessa população, como: origem e destino dos deslocamentos a partir do câmpus Curitiba da PUCPR; horários usuais de chegada e partida dos estudantes; e interesse em oferecer carona.

Nesse processo de aproximação com a temática tendo acesso aos resultados da pesquisa da WRI, também em planilha com dados brutos, os pesquisadores do curso de engenharia civil puderam ainda fazer novos cruzamentos de dados não apresentados inicialmente pela WRI.

A pesquisa de campo junto aos alunos de engenharia civil da PUCPR, se deu no mês de setembro de 2017 com a aplicaçáo de um formulário no início das aulas dos períodos matutino e noturno. O procedimento adotado foi a entrega e explicação do instrumento de pesquisa aos acadêmicos que tinham 10 minutos para preenchê-lo, após esse período o instrumento era coletado pelos pesquisadores. Os dados foram posteriormente tabulados, analisados e sistematizados.

A partir dos dados obtidos foi possível determinar a população a ser abordada dentro da universidade e no curso de engenharia, na perspectiva de sensibilizar para a adesão ao sistema de carona, bem como identificar os sistemas de carona mais efetivos e sustentáveis segundo as características deste grupo.

\section{Resultados}

$\mathrm{Na}$ revisão bibliográfica foram identificados 4 exemplos de sistemas de carona solidária considerados bem sucedidos e com diferentes níveis de interatividade, são eles: Grupos de carona em redes sociais entre alunos na UFPR; aplicativo Caronaê da UFRJ; site Caronetas e Projeto MOB - Carona Solidária da Câmara Legislativa.

As propostas de grupos de carona em redes sociais dentro do campus politécnico da UFPR apresentam facilidades de interação entre alunos, caracterizando-se como uma opção de interface básica para que ocorra a carona. Esta raramente ocorre mediante algum tipo de incentivo financeiro, acontece geralmente entre amigos ou conhecidos. No caso do campus politécnico, existem pontos de 
encontro caracterizados para os interessados em pegar carona [5]. O site Caronetas da UFRJ possibilita que membros de uma organização combinem caronas com colegas de trabalho ou membros de outras organizações cadastradas no site. Dessa forma a interface permite o contato de forma segura de um grande número de usuários provenientes de várias empresas. Além disso, por ser restrito aos colaboradores das empresas participantes, a interface permite ainda a opção de caronas solidárias ou remuneradas [10].

O MOB - Carona Solidária da Câmara Legislativa é uma plataforma dentro da intranet da Câmara dos Deputados em que os funcionários podem se articular oferecendo e recebendo carona. Além de apresentar a possibilidade de incentivos financeiros, o MOB destina vagas exclusivas, dentro do estacionamento destinado a Câmara dos Deputados, para os veículos com ocupação igual ou superior a 2 passageiros [6].

A análise dos sistemas de carona identificados na pesquisa bibliográfica mostrou que os aplicativos de carona dedicados apenas a um público institucional são os que possuem maior confiabilidade e interatividade de interface. Nesse sentido destaca-se o aplicativo Caronaê da UFRJ, em que 81\% dos estudantes reafirmam a importância de ser institucional. Esse sistema conta também com pontos de encontro espalhados pelo campus da Ilha do Fundáo, possibilidade de contrapartida financeira e possibilidade avaliação do usuário [11].

No que se refere à análise dos resultados da pesquisa realizada pela WRI Brasil Cidades Sustentáveis é importante destacar que esta obteve 2.373 respostas, das quais 1.762 foram de alunos e $24 \%$ destes pertenciam à escola politécnica. A divisão modal dos alunos da universidade pode ser observada abaixo na Figura 1 [12].

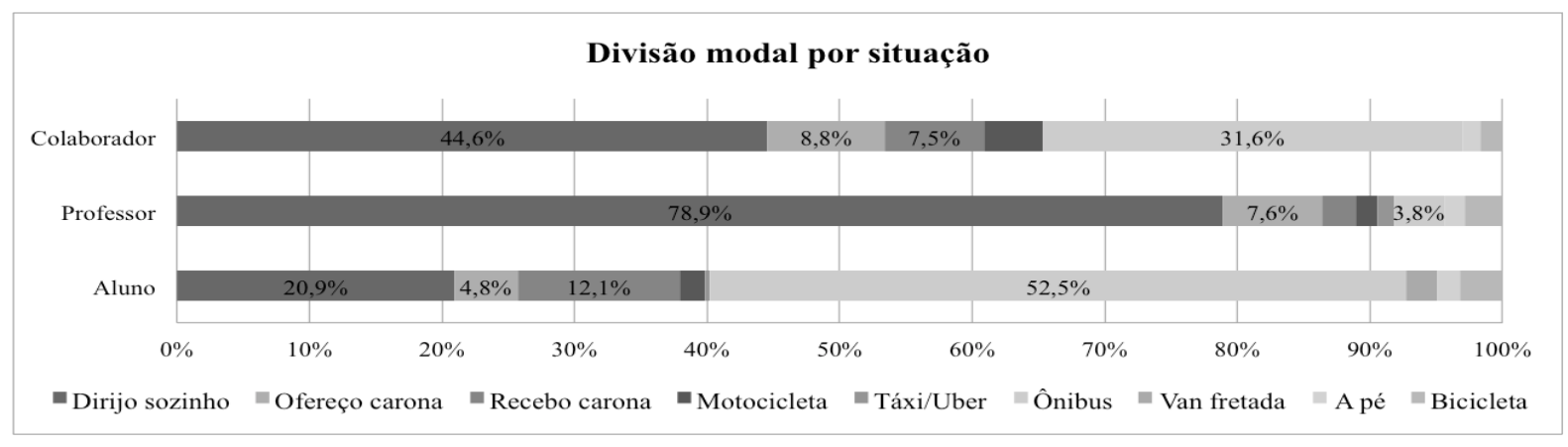

Figura 1 - Divisão modal por situação.*

Pode-se observar que cerca de 20,9\% dos estudantes dirigem sozinhos, representando uma população de cerca de 5.664 condutores diários. No que se refere ao modal alternativo ao transporte individual, $49 \%$ dos respondentes consideram receber ou oferecer carona como primeira opçáo, como posto na Figura 2 [12]. 


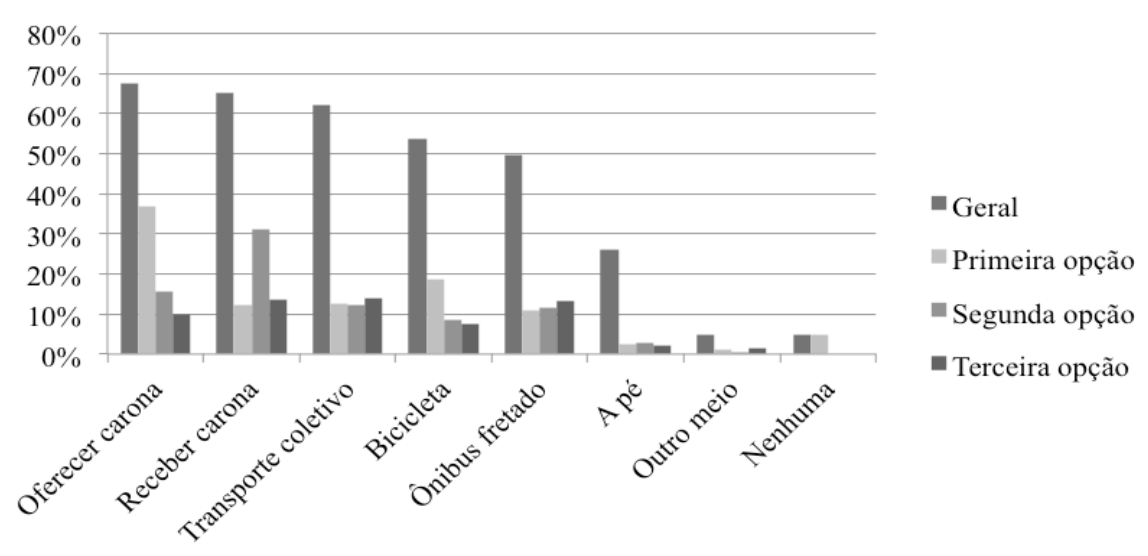

Figura 2 - Alternativas ao veículo individual em ordem de interesse.

Alternativas quanto às condiçóes que levariam os condutores a oferecer carona foram apresentadas para os 735 estudantes e professores que utilizavam o veículo diariamente segundo a pesquisa. Os resultados estão evidenciados nas Figuras 3, 4 e 5 [12].

Pode-se identificar que alternativas de ordem econômica como desconto no estacionamento (30\%) e divisão de custos (22\%) representam os principais fatores de incentivo, seguido por fatores de praticidade e acessibilidade (28\%) e por fim fatores de impessoalidade como carona só entre amigos (5\%), somente entre colegas de curso (11\%) e unicamente entre colegas de escola (9\%).

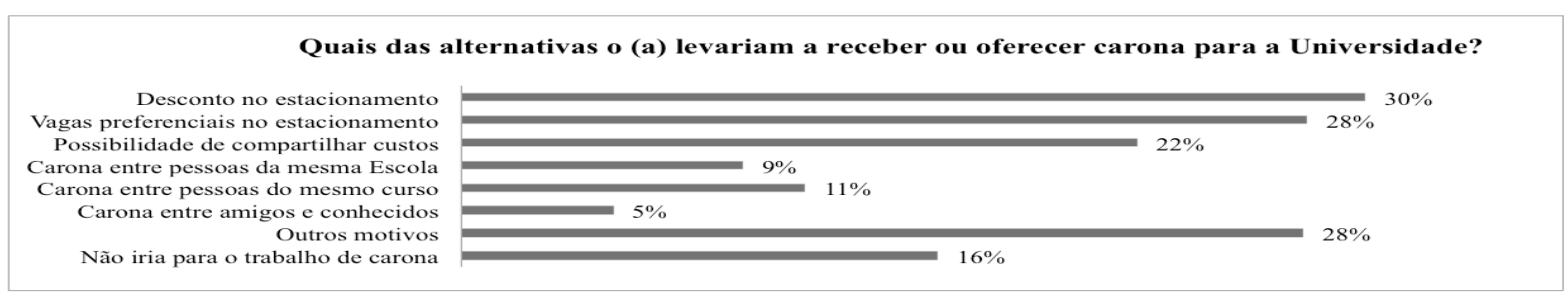

Figura 3 - Alternativas que incentivariam a oferecer carona.

Entre aqueles que oferecem carona, foi identificado que $58 \%$ da população estudada se dispóem a esperar até 15 minutos. No que se refere ao desvio de rota $74 \%$ dos pesquisados manifestaram a possibilidade de desvio de até $1 \mathrm{~km}$. 


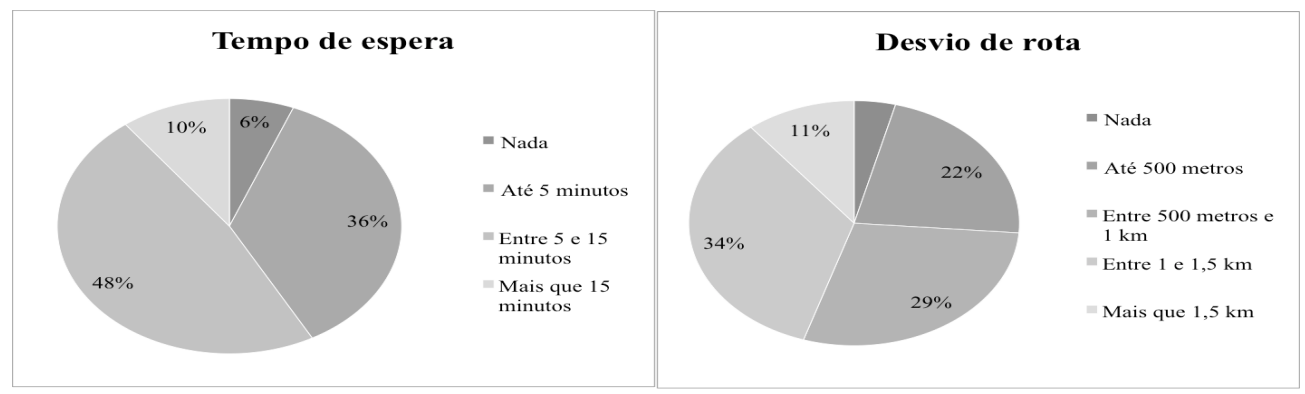

Figura 4 - Interesse dos condutores em esperar ou desviar sua rota.

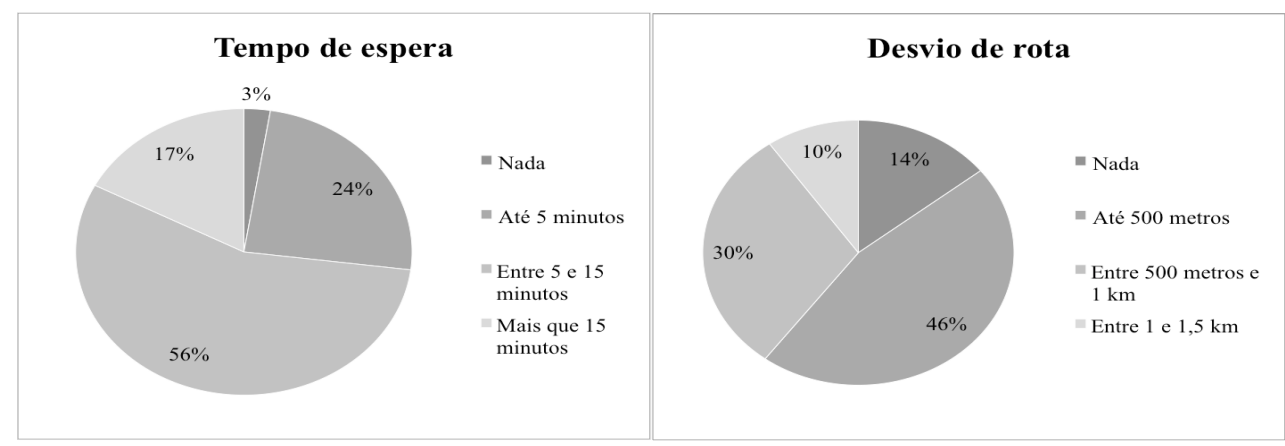

Figura 5 - Interesse dos caronas em esperar ou desviar sua rota.

Já em relação àqueles que recebem carona, foi identificado que $73 \%$ da população estudada, disponibilizam-se a esperar mais de 15 minutos. No que se refere ao desvio de rota $40 \%$ dos pesquisados aceitam o desvio de $1 \mathrm{~km}$ ou mais. Os fatores econômicos da prática da carona estão evidenciados na Figura 6 [12].

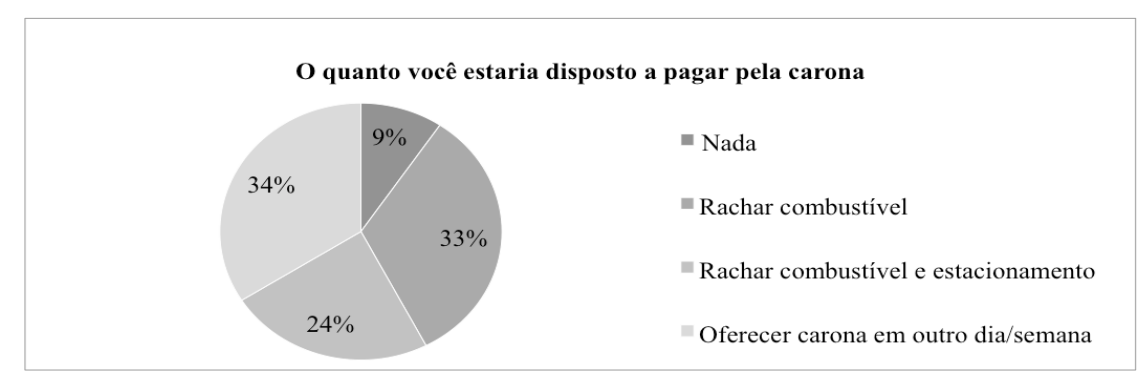

Figura 6 - Quais recompensas financeiras seriam mais atrativas.*

A pesquisa realizada pelos acadêmicos junto ao curso de engenharia civil da PUCPR atingiu uma amostragem de 464 estudantes, ou seja, aproximadamente 38\% do total de discentes do curso, sendo que, segundo a pesquisa, 53\% (287) dos alunos moram e/ou trabalham em um raio de até 5 $\mathrm{km}$ da universidade, 84\% (457) em um raio de até $10 \mathrm{~km}$, e 94\% (513) em um raio de até $15 \mathrm{~km}$. Deste universo, 291 estudantes utilizam automóvel individual diariamente para ir à universidade. $\mathrm{O}$ interesse em oferecer carona é apresentado na Gráfico 7. 


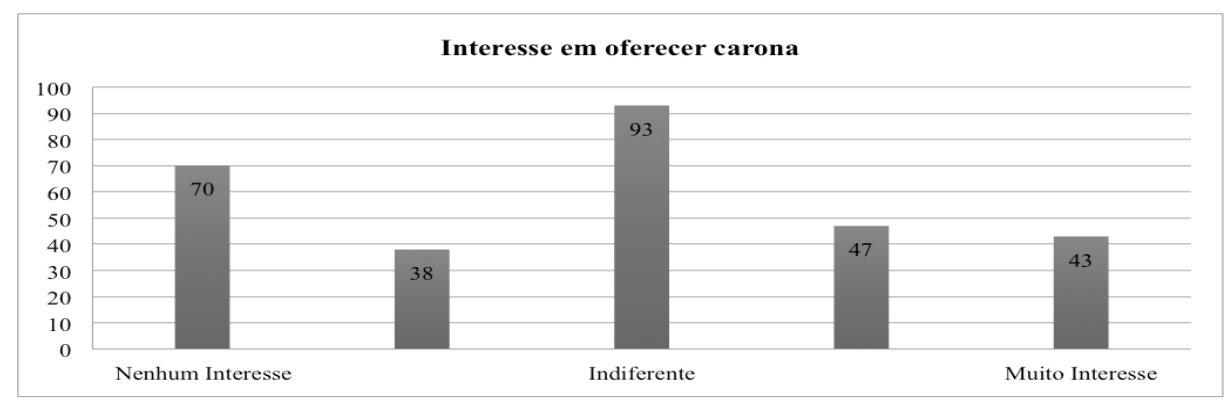

Figura 7 - Interesse em oferecer carona.

Dentre a subpopulação de estudantes do curso de engenharia civil da PUCPR foi identificado um grupo de 93 estudantes (20,1\% da subpopulação) que são indiferentes quanto à proposta de carona.

\section{Conclusóes}

A partir da análise e sistematização de dados identificou-se uma população de 93 estudantes (20\% dos participantes) que seriam potenciais ofertantes de carona e, portanto, o público-alvo a ser trabalhado e incentivado a participar de sistemas de carona.

As propostas mais efetivas de estímulo para utilização do sistema carona identificadas no processo de pesquisa foram as de incentivo econômico. Dentre estes destaca-se a contribuiçáo no custo da gasolina e o compromisso de oferecer carona em uma outra oportunidade. Essa última possibilidade abre a discussão para a criação de um sistema de recompensa interno, que não se traduza em uma proposta monetária, como vale carona, créditos ou pontos que poderiam ser válidos na utilização de serviços e parceiros da universidade. Considera-se serviços internos e parceiros, os serviços de fotocópia, as cantinas, as atividades esportivas, o estacionamento, e as lojas internas.

Outro resultado a ser destacado, foi o interesse manifesto pelo condutor de desviar a rota em até $1,5 \mathrm{~km}$ de distância e em esperar até 15 minutos para oferecer carona. No que se refere ao usuário da carona, este se dispôs a desviar a rota em até 1,0 km de distância e esperar até 15 minutos. Poder-se-ia aqui propor a criação de um aplicativo de carona, nos moldes do aplicativo Caronaê desenvolvido por estudantes e professores da UFRJ, destacando-se sua interatividade, facilidade de utilização, segurança, baixo custo e os pontos de parada espalhados pela cidade universitária da Ilha do Fundão. Deve-se levar em consideração a importância de que a PUCPR promova similar proposta, principalmente, fomentando a participaçáo conjunta do seu corpo discente e docente no desenvolvimento do produto em questáo. Tal iniciativa, favoreceria a apropriação desse sistema pelos estudantes, posto sua contribuição no processo, aumentando a adesão destes ao sistema.

Como segundo fator que mais motivaria os estudantes a oferecer carona sobressai aqueles relacionados a acessibilidade, como a possibilidade de criaçáo de vagas preferenciais no estacionamento. 
E por fim, quanto à pessoalidade, propostas voltadas para acadêmicos de um mesmo curso são mais atrativas, englobando até $95 \%$ dos interessados em oferecer carona.

Levando em consideração a população de condutores do curso de engenharia civil como sendo aproximadamente 754 , pode-se afirmar que a implementação bem sucedida de sistemas de carona que elevasse a taxa de ocupação média mínima de 2 passageiros por veículo teria potencial de atender integralmente os alunos do curso de engenharia civil. Poderia ainda representar uma diminuição de aproximadamente 376 veículos uma vez que $49 \%$ dos respondentes utilizariam a carona como principal alternativa ao veículo individual.

Dada a riqueza de dados obtidos a partir das pesquisas e do interesse institucional em encontrar soluçóes que diminuam o número de áreas de estacionamento no interior do campus principal da universidade, existe um vasto horizonte de pesquisa a ser desenvolvido neste tema. Dentre as principais frentes de pesquisa destacam-se: estudo a respeito da criação de aplicativo de carona interno na PUCPR, quanto à interface e operabilidade; determinação de estratégias que permitam a utilização da carona como um sistema perene; e estudo para redução do estacionamento caso um sistema de carona funcional fosse implementado.

\section{Referências}

[1] VASCONCELLOS, E. A. Políticas de transporte no Brasil: A construção da mobilidade excludente. Barueri, SP: Ed. Manole, 2013. p. 27-97.

[2] COULAUD, D. L'automoville: Ville, automoville et mode de vie. Paris: L'Harmattan, 2010. p. 9-16.

[3] CASAGRANDE, Renato; FREITAS FILHO, Roberto. O problema do tempo decisório nas políticas públicas. Revista de Informaçáo Legislativa, Brasília, v. 187, n. 47, p.21-34, set. 2010. Mensal.

[4] GAULTIER, Élise. Agir ensemble pour des mobilité urbaines durables: Du quartier au territoire. Paris: Comité 21, 2014. p. 76-84.

[5] MENDES JUNIOR, Ricardo; FUSCO, Rafael. Projeto Carona Solidária na UFPR. 2011. 10 f. Monografia Curso de Arquitetura e Urbanismo, Universidade Federal do Paraná, Curitiba, 2011.

[6] GLOBOTV. Câmara dos deputados estimula a carona solidaria através de aplicativo. Disponível em: <http:// globotv.globo.com/rede-globo/dftv-2a-edicao/v/camara-dos-deputados-estimula -a-carona-solidaria- atraves-deaplicativo/3893449/>. Acesso em: 11 de out. 2017.

[7] MONTAÑO, Carlos E.. Terceiro Setor: Crítica ao padrão emergente de intervenção social. São Paulo: Cortez, 2002. 288 p. (214-229).

[8] SILVA, Diane Bianchi da Costa e. Transporte Solidário: uma rede colaborativa para cidades mais sustentáveis. 2015. 63 f. Monografia (Especialização) - Curso de Engenharia Urbana, Universidade Federal do Rio de Janeiro, Rio de Janeiro, 2015.

[9] Ecotécnica - Tecnologia e Consultoria. Estudo de Polo Gerador de Tráfego - PUCPR - Campus Curitiba. Curitiba, 2017.342 p.

[10] CARONETAS. CARONETAS. Disponível em: <https://www.caronetas.com.br>. Acesso em: 12 de out. 2017.

[11] MEYER et al. Transporte Solidário - Unificando e Ampliando as Caronas na Cidade Universitária da UFRJ. Concurso Soluçôes Sustentáveis: termo de referência, Fundo Verde, Universidade Federal do Rio de janeiro, 2014.

[12] WRI Ross Centro para Cidades Sustentáveis, Projeto de Mobilidade Corporativa: Relatório Final de Diagnóstico da PUCPR. Curitiba, 2017. 